\title{
Ultimate attainment of second language articles: A case study of an endstate second language Turkish-English speaker
}

Second Language Research 26(4) 527-548

(c) The Author(s) 2010 Reprints and permission: sagepub. co.uk/journalsPermissions.nav DOI: 10.1 I77/0267658310377/02 http://slr.sagepub.com

(\$SAGE

\author{
Neal Snape \\ Gunma Prefectural Women's University, Japan
}

\section{Tanja Kupisch}

University of Hamburg, Germany

\begin{abstract}
An area of considerable interest in second language (L2) acquisition is the difficulties learners face with the acquisition of articles. This article examines the role of prosody in the acquisition of articles by an endstate L2 English speaker focusing on the free morphemes the and $a$. In order to analyse the articles produced by a Turkish speaker named SD, we used the Praat (Boersma and Weenink, 2006) phonetic analysis software to determine the prosodic shape of each article in article + noun configurations and article + adjective + noun configurations. The aim of the analysis is to see whether a more detailed analysis of the data would be fully consistent with the strong or weak interpretation of the Prosodic Transfer Hypothesis. The findings of our analysis show that SD produces a large percentage of stressed articles, which are non target-like. We discuss the implications of our analysis for the interlanguage representation of articles by SD as well as the Prosodic Transfer Hypothesis.
\end{abstract}

\section{Keywords}

second language acquisition, universal grammar, ultimate attainment, prosodic transfer hypothesis, stress, prosodification Turkish, definite article, indefinite article

\section{Introduction}

Over the past few years there have been a number of studies investigating the acquisition of articles by second language (L2) learners of English. For example, Ionin et al. (2004) made predictions about L2 learners' incorrect use of English articles, claiming that

\footnotetext{
Corresponding author:

Neal Snape, Department of English, Faculty of International Communication, Gunma Prefectural Women's

University, I395-I Kaminote, Tamamura-machi, Sawa-gun, Gunma-ken, 370-I I93, Japan

Email: nealsnape@gpwu.ac.jp
} 
learners sometimes use definite articles instead of indefinite articles and vice versa because they fluctuate between parameter settings in which articles either encode definiteness or encode specificity. White (2003), Lardiere (2004), White (2008) and White et al. (2009) focused on definiteness effects, arguing that advanced L2ers become sensitive to the definiteness effect in English, even if the first language (L1) lacks an article or articles. Others, such as Young (1996), Trenkic (2002) and Snape (2008a), have investigated how the English article system interacts with the count/mass distinction showing that article selection is a complex process based on noun type. Hawkins et al. (2006) and Snape (2008b) proposed a feature-based account for how the features definiteness and specificity are selected and encoded semantically in L2 learners' interlanguage grammars, arguing that, as a result, individual interlanguage grammars may differ from each other. For example, unlike in Ionin et al.'s (2004) account, some learners select the feature definiteness, whilst other learners select the feature specificity. Most L2 studies have focused on semantic or pragmatic related properties of articles. The focus of our article is on L2 article production and whether or not the L1 prosodic representations are involved in the representation of articles in L2 English.

Discussion of the prosodification of articles has generally been related to how children prosodify articles in the first language (L1) (e.g. Lleó and Demuth, 1999; Goad and Buckley, 2006; Demuth and Tremblay, 2008; Demuth and McCullough, 2009; Kupisch et al., 2009). Recently, Goad and White (2004, 2006a) have investigated the L2 acquisition of English articles by Turkish and Chinese learners. One of the motivations for providing a prosodic account is to investigate why L2 learners sometimes fail to provide functional morphology in obligatory contexts. Variability in L2 production focuses not just on the presence or absence of overt bound morphology (e.g. past tense -ed, third person agreement $-S$, plural $-s$ ), but also on how morphology is produced and represented prosodically in L2 grammars. Omission of morphology may result from different prosodifications in L1 and L2. Specifically, learners omit articles when the L1 prosodic structure cannot be used to represent articles and other functional morphemes in the L2. This position is known as the Prosodic Transfer Hypothesis (PTH) (Goad et al., 2003; Goad and White, 2006b, 2007, 2009a, 2009b).

White (2003) collected naturalistic longitudinal data from a native speaker of Turkish, named SD, who is an advanced learner of English currently residing in Canada. Four interviews were conducted during a two month period (referred to as Time 1) and then 18 months later a fifth interview (referred to as Time 2) was conducted. Goad and White (2004) re-examined the data and found that SD was able to supply articles in article + noun $(\operatorname{art}+\mathrm{n})$ configurations (e.g. the/a man), and article + adjective + noun $(\operatorname{art}+\operatorname{adj}+n)$ configurations (e.g. the/a young man), but articles in these obligatory contexts were being supplied inconsistently. Goad and White (2006a) found that Turkish and Chinese L2 learners omit articles or use strategies such as supplying a demonstrative (e.g. this man), or a numeral (e.g. one man), in the place of an article. They argued that the reason for variability in suppliance of articles is due to the L1 lacking corresponding prosodic structures. These data are consistent with Goad and White's PTH, according to which L2 learners' syntactic representations may be target-like. Nevertheless, L2 learners may delete functional material in production if the prosodic structure in their L1 differs. However, if the L1 prosodic structure can be modified to accommodate the L2, then the PTH 
predicts far greater accuracy in suppliance of functional morphology by L2 learners, perhaps reaching native-like levels in production. Further discussion of possible interlanguage representations of articles by Turkish speakers is discussed in Section III of the present article.

Recently, Goad and White (2009a) have proposed that there are two versions of the PTH: (1) the strong interpretation and (2) the weak interpretation. Under the strong interpretation of the PTH the target prosodic structure for English articles (see Figure 2d) will not be acquirable by Turkish speakers. This implies that they either omit articles or produce them with a target-deviant prosody. A weaker interpretation is that the target prosodic structure should be particularly difficult to acquire, only emerging in the interlanguage grammars of highly proficient L2 learners. The two interpretations of the PTH are discussed further in Section IV.

In the present article we focus on article suppliance in production. We are only concerned with the data collected in the final interview, interview 5, as Goad and White (2004) claim that SD has reached a steady state in her L2 English. The aim of the article is to present a prosodic analysis of articles produced by SD to see whether or not articles are target-like (unstressed) or non target-like (stressed) at a steady state of L2 acquisition. In previous work by White (2003) and Goad and White (2004) the data were analysed and their discussion included the omission of articles in obligatory singular count noun configurations, e.g. * ' $\varnothing$ dog', and in singular count noun configurations with an adjective, e.g. * ' $\varnothing$ brown dog'. 'Omissions of articles are referred to as deletion under the PTH as learners may delete functional material, such as articles, if the L1 lacks corresponding prosodic structures or if learners fail to build new prosodic representations to accommodate articles in the interlanguage grammar.

Trenkic (2007) investigates omission of articles by L1 Serbian learners of English and argues that Serbian, unlike Turkish, has prosodic structures available in the L1, which can be adapted and used to represent L2 articles. She proposes a processing account for the omission of articles found in $\operatorname{art}+\mathrm{adj}+\mathrm{n}$ configurations, arguing that L1 Serbian learners misanalyse English articles as nominal modifiers. The production of misanalysed elements cannot be syntactically motivated and therefore causes problems in production. ${ }^{2}$ As we are concerned with the prosodic shape of articles supplied by an endstate Turkish speaker of English, we leave aside discussion about the omission of articles in the present article. The aim of the reanalysis is to look at articles produced by SD using the acoustic analysis program Praat. To this end we wanted to find out whether the results of our analysis would be consistent with the claim by Goad and White (2006a, 2006b) that L2 speakers employ strategies before acquiring the target structure (if it is possible to acquire L2 structures absent in the L1) such as stressing the article or substituting articles with demonstratives or numerals. Both of these strategies would result from transferring L1 prosodic structures into the L2. What we hope to achieve from our analysis is a more detailed account of article suppliance by an endstate speaker of English. To our knowledge, no other study in the L2 literature has provided a detailed phonetic analysis of articles, apart from Goad and White (2009b), where they analyse vowel harmony in Turkish. We discuss the implications of our analysis for the interlanguage representation of English articles and suggest how our findings support the strong version of the PTH. 
In Sections II and III of the article details of nominals in Turkish and English are given and how the two languages differ in prosodic structure at the left edge in $\operatorname{art}+\mathrm{n}$ and $\operatorname{art}+\operatorname{adj}+\mathrm{n}$ configurations, i.e. the position hosting the article.

\section{The nominal domain of English and Turkish}

As already mentioned in the introduction, our focus is on the acquisition of English articles (the/a) in obligatory singular count noun $(\mathrm{CN})$ configurations by an L1 speaker of Turkish. English differs to Turkish in that there are two articles which encode [+/-definite], the being the definite article and $a$ the indefinite article. Singular CNs must be syntactically licensed by an article (1a), but English allows bare plural (1c) and mass nouns (1d) (no licensing by $\mathrm{D}$ required), otherwise they are ungrammatical as bare nouns, as shown in (1b).

(1) a. a boy, the boy [-/+definite] [singular $\mathrm{CN}]$

b. *boy

c. boys [-definite] [plural CN]

d. furniture [-definite] [mass noun]

Turkish has no definite article. Definiteness is marked only with accusative Determiner Phrases (DPs), which take an accusative case suffix when they are definite, as in example (2).

(2) Ali kitab-1 okudu.

Ali book-acc read

'Ali read the book.'

In subject position in example (3), bare nouns can be either definite or indefinite (with arbitrary reference), although bare subject DPs are usually definite, because the sentence initial position is generally occupied by topics.

(3) Çocuk güldü.
child
'The child laughed.'

(from Öztürk, 2005)

The examples in (4) show the difference between specific and non-specific noun phrases (the accusative suffix is a marker of specificity here).

(4) a. Ali bir kitap okudu. Ali a book read

(non-specific indefinite)

'Ali read a book.'

b. Ali bir kitab-1 okudu.

Ali a book-acc read

'Ali read a certain book.'

(indefinite specific)

(from Öztürk, 2005)

While bare nominals can be definite or indefinite (see 5a), prenominal bir attributes an indefinite reading to the noun when it is unstressed (see 5b) or it is interpreted as the numeral one if stressed, as in (5c). Demonstratives are stressed in (5d) and (5e). 
(5) a. kitáp '(the/a) book'

b. bir kitáp 'a book'

c. bír kitap 'one book'

d. bú kitap 'this book'

e. bú kırmızı kitap 'this red book'

Öztürk (2005) argues that Turkish is a language which lacks the syntactic category DP, unlike English which has a fully specified DP (Abney, 1987). Though Turkish lacks the morphological equivalents of the and $a$ found in English, there is some disagreement in the literature as to whether unstressed bir is an article (see Kornfilt, 1997), a numeral (see Underhill, 1976), a quasi indefinite article (Lyons, 1999), or a predicate modifier (Öztürk, 2005). For the purposes of our analysis we assume that Turkish has a morpheme similar to an article in English though the prosodic representation of bir differs from English articles the/a.

\section{Prosodic structures in English and Turkish}

In this section we discuss the English prosodic representations of articles and the Turkish prosodic representations of bir. The hierarchy of prosodic constituents, based on Selkirk (1986), is organized into syllables, feet, prosodic words (PWd) and phonological phrases $(\mathrm{PPh})$, as illustrated in Figure 1. Selkirk (1996) identifies three types of clitics, where the function (fnc) word could be an independent prosodic word, an internal clitic (Figure $2 b$ ), an affixal clitic (Figure 2c) or a free clitic (Figure 2d). Internal clitics are organized internal to the PWd as in Figure $2 \mathrm{~b}$ and in this regard they respect the constraints on prosodic domination. Affixal clitics involve adjunction to the PWd as in Figure $2 \mathrm{c}$ and free clitics (see Figure 2d) do not involve adjunction to the PPh. The lexical word (base)

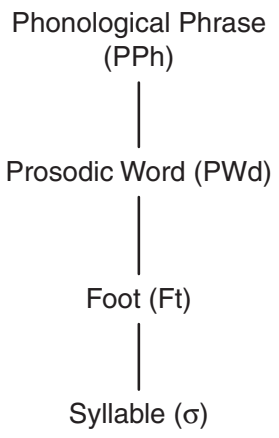

Figure I The prosodic hierarchy (partial) Source: based on Nespor and Vogel, 1986; Selkirk, 1986 
a. independent PWd

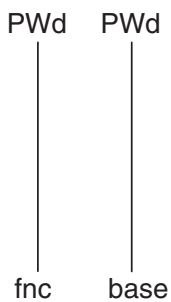

b. internal clitic

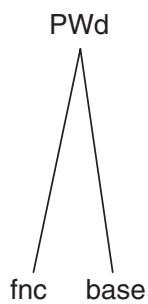

c. affixal clitic

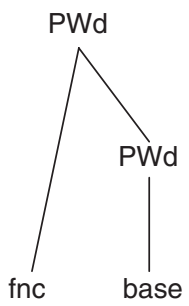

d. free clitic

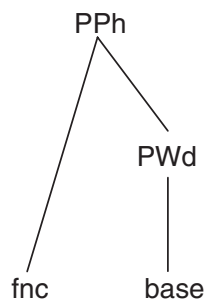

Figure 2 Prosodic word and clitics

is prosodified as an independent prosodic word. Under Selkirk's (1996) analysis English articles are free clitics (see Figure 2d), with other languages exploiting other options. Turkish is a language which exploits the structure in Figure 2c.

The difference between English and Turkish is that in English, articles are free clitics in $\operatorname{art}+n$ and $\operatorname{art}+\operatorname{adj}+n$ configurations, which attach directly to the PPh. Examples in (6) show how the article (the/a) attaches directly to the $\mathrm{PPh}$ in art $+\mathrm{n}$ configurations and in $\operatorname{art}+\operatorname{adj}+n$ configurations.

(6) a. [a [mán $\left.]_{\mathrm{PWd}}\right]_{\mathrm{PPh}}$

b. $\left[\text { the }[\mathrm{mán}]_{\mathrm{PWd}}\right]_{\mathrm{PPh}}$

c. $\left[\mathrm{a}[\text { good }]_{\mathrm{PWd}}[\mathrm{mán}]_{\mathrm{PWd}}\right]_{\mathrm{PPh}}$

d. [the $\left.[\text { good }]_{\text {PWd }}[\text { mán }]_{\text {PWd }}\right]_{\text {PWh }}$

In Turkish, Goad and White (2004) argue unstressed bir is an affixal clitic that adjoins to the PWd, which then links higher to the PPh (Figure 3a). ${ }^{3}$ The relevant prosodic structures for Turkish are supplied in Figure 3. Stressed bir is analysed as a separate foot, which can form its own prosodic word (see Figure 3b). Evidence supporting the claim that (unstressed) bir is an affixal clitic, not a free clitic, comes from adjectival configurations, as in (7).

a. Turkish indefinite article (unstressed):

Affixal clitic (prefix)

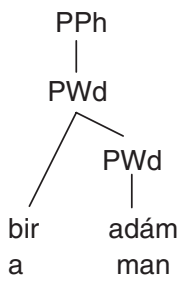

b. Turkish numeral (stressed): Independent PWds

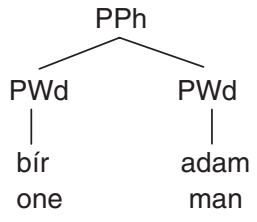

Figure 3 Prosodic structures of Turkish determiners

Source: adapted from Goad and White, 2004: I3 I 
(7) a. iyí bir adam

good a man

'a good man'

b. * bir iyi adam

a good man

c. bír iyi adam

one good man

The canonical word order is evidenced in (7c). The difference between (7a) and (7b) is that indefinite bir cannot have an intervening adjective placed between it and the noun. Goad and White (2004) claim the reason for (7a) being well-formed is that indefinite bir attaches as a prefix onto the head noun adam. In example (7b) the adjective separates the unstressed indefinite article and noun, and as bir cannot prefix onto an adjective the structure is ill-formed, given the structure in Figure 4b. It seems that indefinite bir is prosodically dependent on the head noun, rather than the phrase, because it is cliticized onto the noun. However, numeral bir is stressed and is an independent PWd, as represented in Figure 4c.

Goad and White (2004) suggest possible representations of articles in SD's interlanguage grammar, all of which are possible structures in Turkish (for the affixal clitic

(a)

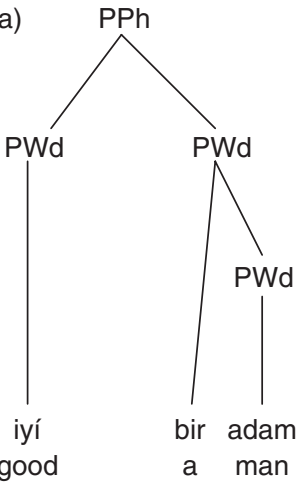

(b)

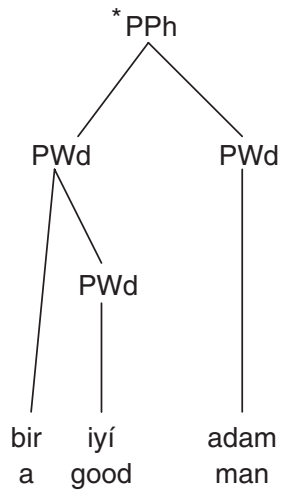

(c)

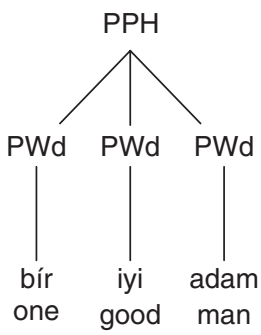

Figure 4 Prosodic representations of bir Source: Goad and White, 2009b: 8 
a. Affixal clitic

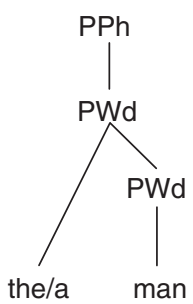

b. PWd-internal

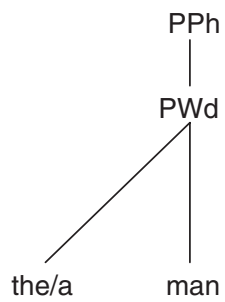

c. Stressed article

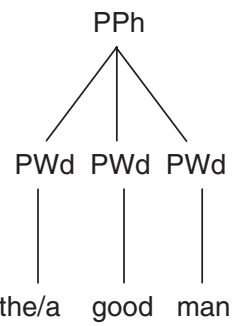

Figure 5 Possible interlanguage prosodic representations (LI Turkish, L2 English)

representation see further below and especially Figure 6a). These are illustrated in Figure 5. Goad and White (2004) argue that there is L1 transfer and propose the prosodic representation in Figure 5a, which uses adjunction to the PWd. This allows them to predict contrasts between art $+n$ DPs and $\operatorname{art}+\operatorname{adj}+n$ DPs. They predict that SD will be able to prosodically represent articles in art $+n$ configurations as the article can adjoin to the PWd, as illustrated in Figure 5a, as this structure is available in the L1 (see Figure 3a). It is important to note that although the article may sound target-like it will not be a targetlike free clitic. However, in $\operatorname{art}+\mathrm{adj}+\mathrm{n}$ configurations articles cannot adjoin to adjectives within the PWd in English. The corresponding structure in Turkish is adj+art $+n$, as illustrated in Figure 4a. Crucially for their analysis, it differs to the art + adj $+n$ structure of English. Therefore, it is predicted that there will be more deletion in the latter type of configuration than in simple art $+\mathrm{n}$ configurations and this is what Goad and White (2004) partially found in the data. Systematic omission of articles in $\operatorname{art}+\operatorname{adj}+\mathrm{n}$ configurations is not predicted as in some cases articles may be produced as independent PWds (stressed) rather than clitics (unstressed).

In the analysis of $\operatorname{art}+\mathrm{adj}+\mathrm{n}$ configurations in Turkish provided by Goad and White (2004) there is no way that indefinite bir can prefix onto the adjective as the resulting representation is illicit (see Figure 4b). However, Goad and White (2004) considered a PWd-internal analysis for articles in art $+n$ configurations. They proposed that in SD's interlanguage grammar the right edge (prosodification of tense, agreement and plural) in Turkish is adapted to represent articles in L2 English at the left edge. However, whether this is possible depends on where stress is assigned on the following noun. One example where the article could appear within the PWd in SD's interlanguage grammar is when stress is assigned to the first syllable (see Figure 6a). The word sófa has initial stress so the article could link directly to the PWd, but in English it links to the PPh (see Figure 6b). 
a. Interlanguage rep: $a r t+n$

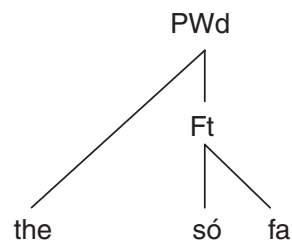

b. English rep: art+n

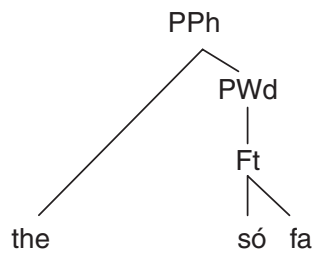

Figure 6 Initial syllable stress: A possible interlanguage representation Source: Goad and White, 2004: I 35

However, if stress is assigned to the second syllable of a noun such as police the first syllable must appear outside of the foot and attach directly to the PWd, as in Figure 7. The article in Figure 7a is not permitted in English to appear as an unfooted syllable because this means that there are two unfooted syllables, and the structure with two unfooted syllables in a row is illicit, i.e. $\left[\mathrm{po}(\text { líce })_{\mathrm{Ft}}\right]_{\mathrm{PWd}}{ }^{*}\left[(\text { pólice })_{\mathrm{Ft}}\right]_{\mathrm{PWd}}$. Unfortunately, there were few nouns with second syllable stress in the data set, so the location of where stress fell on the noun could not be investigated.

To summarize, English and Turkish differ morpho-syntactically and prosodically in the nominal domain. English has an indefinite and a definite article, while Turkish only has an indefinite article which is homophonous with the numeral bir. English articles are free pro-clitics, while Turkish bir is represented as a separate independent PWd (if it constitutes a numeral) or as an affixal clitic (if it constitutes an indefinite article).

\section{Prosodic Transfer Hypothesis (PTH)}

\section{Strong and weak interpretations of the PTH}

Goad and White (2004) propose the notion of minimal adaptation, as outlined in (8).

(8) Minimal adaptation in prosodic structure:

a. L2 structures are possible in the interlanguage grammar when they can be built through a combination of pre-existing licensing relations.

b. L2 structures are possible in the interlanguage grammar when they involve L1 structures being licensed in new positions. (from Goad and White, 2004: 127)

Goad and White (2004) argue that under the strong interpretation of the PTH a high percentage of deletion could be accounted for under either of the conditions in (8) if L2 learners are unable to build new prosodic representations to accommodate inflectional morphology as they may only have partial access to Universal Grammar (UG) in the domain of prosodic phonology. L2 learners might not be able to build new prosodic representations because it is not possible to escape from the constraints imposed by the L1 prosodic phonology. In other words, there may be full transfer of the L1 in the domain of prosodic phonology, but not full access (cf. Schwartz and Sprouse, 1996). 
a. Interlanguage rep: $a r t+n$

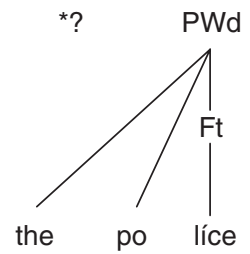

b. English rep: art+n

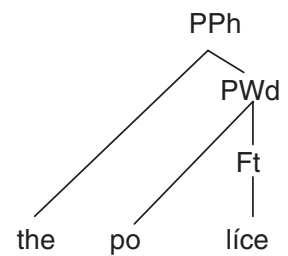

Figure 7 Second syllable stress: An impossible interlanguage representation Source: Goad and White, 2004: 130

Under the weak interpretation of the PTH, new prosodic structures can be built under conditions other than those in (8). L2 learners may be able to adapt L1 structures in a new location in the interlanguage grammar, i.e. in a position where it is not licensed in the L2 (or neither L1 nor L2). For example, Turkish allows PWd internal clitics with tense affixes, but not with articles. In the interlanguage grammar, we may find PWd internal clitics being represented with functional morphemes other than tense affixes, e.g. articles. In more recent work by Goad and White (2009a) they found evidence for restructuring under the two conditions stated in (8), which is not predicted to take place under the strong interpretation. Three proficient Turkish speakers of English were able to build new prosodic representations under the conditions stated in (8).

Before discussing our predictions in the next section we provide the results from all five interviews of SD's suppliance of articles in obligatory contexts in Tables 1 and 2 below. Tables 1 and 2 show that even though SD omits articles in obligatory contexts she is able to supply a large number of definite and indefinite articles in both $\operatorname{art}+\mathrm{n}$ and $\operatorname{art}+\mathrm{adj}+\mathrm{n}$ configurations. However, there is far less suppliance of indefinite articles in $\operatorname{art}+\operatorname{adj}+n$ configurations $(49 \%)$ than indefinite articles in art $+n$ configurations $(70 \%)$. We will discuss possible reasons for the asymmetry found between the suppliance of indefinite articles in Section VIII.

Table I Articles produced in art $+n$ configurations

\begin{tabular}{lll}
\hline & Definite & Indefinite \\
\hline Supplied & $277 / 361(77 \%)$ & $231 / 329(70 \%)$ \\
\hline
\end{tabular}

Table 2 Articles produced in art $+a d j+n$ configurations

\begin{tabular}{lll}
\hline & Definite & Indefinite \\
\hline Supplied & $61 / 91(67 \%)$ & $121 / 245(49 \%)$ \\
\hline
\end{tabular}

Source: adapted from Goad and White, 2004: I 34 


\section{SD's interlanguage representations}

\section{Predictions}

As discussed in Section II, Turkish is a language without articles (although in specific contexts, the numeral bir has come to be used with indefinite marked nominals). One option for Turkish speakers considered by Goad and White (2009a) is to represent unstressed articles in art $+\mathrm{n}$ and $\operatorname{art}+\mathrm{adj}+\mathrm{n}$ configurations by adapting an existing L1 structure, as illustrated in Figures $8 \mathrm{a}$ and $8 \mathrm{~b}$. We do not consider the PWd-internal structure (see Figure $5 \mathrm{~b}$ above) as there were few nouns with second syllable stress in the dataset.

SD should have no difficulty with representing unstressed articles in art $+\mathrm{n}$ configurations as this structure (Figure 8a) is available in the L1. It will be more difficult to represent unstressed articles in art $+\mathrm{adj}+\mathrm{n}$ configurations as the structure is not available in the L1 (Figure $8 \mathrm{~b}$ ), so SD must modify the existing structure to accommodate unstressed articles. If the article receives stress it has the representation given in Figure $5 \mathrm{c}$, repeated below in Figure 9.

Thus, L1 Turkish licensing options provide no way to associate articles directly with the $\mathrm{PPh}$ (the structure required for English; see Figure 2d). This leaves two alternative representations which could be used, based on available L1 structures: (i) non-target-like adjunction to PWd (required for indefinite bir in Figure 3a) might be used in the interlanguage grammar to represent unstressed articles; (ii) if articles receive stress they form their own independent PWds. The following predicted patterns are based on Goad and White (2006a).

a.

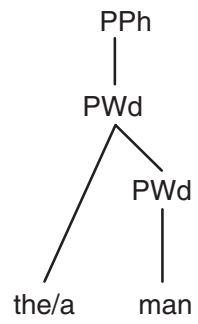

b.

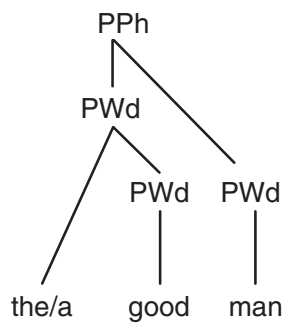

Figure 8 Interlanguage representations for unstressed articles in art+n and art $+a d j+n$ configurations

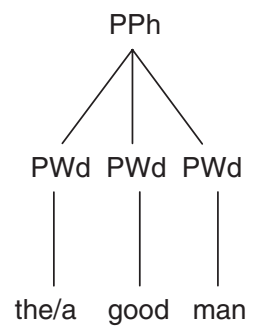

Figure 9 Interlanguage representation for stressed articles in art $+a d j+n$ configurations 
1. Appropriate use of determiners other than articles (e.g. demonstratives), since these are represented as independent PWds in both languages.

2. Substitution of other determiners in place of articles, e.g. one for $a$ and demonstratives for the, in accordance with Figure $3 \mathrm{~b}^{4}$

3. Adoption of strategies which allow articles (or article-like elements) to be supplied while bypassing the structure in Figure 2d, including: (a) stressing of articles and (b) deletion of articles.

4. Greater difficulties in article suppliance for SD when DPs include both articles and adjectives, given the affixal clitic structure in Figures $3 \mathrm{a}$ and $4 \mathrm{a}$ for nominals in the $\mathrm{L} 1$, in contrast to the free clitic representation in $(6 \mathrm{a}-6 \mathrm{~d})$ required in the $\mathrm{L} 2$.

Under the strong interpretation of the PTH the target prosodic structure for English articles will not be acquirable by Turkish speakers. The weaker interpretation predicts that though the target free clitic representation in English is difficult to acquire proficient speakers of the L2 should show greater target-like suppliance of articles, i.e. fewer stressed articles, in their interlanguage grammars. We predict that under the strong interpretation of the PTH it will be difficult for SD to overcome the effects of the L1 structure as she is an advanced fossilized learner. But, under the weak interpretation of the PTH it is possible that SD can build new representations as she is a highly proficient speaker of English.

\section{Coding procedure}

Article suppliance by three native speakers of English was examined and compared with SD's article suppliance (from interview 5) to see whether SD's articles were stressed (non target-like) or unstressed (target-like). There were significant differences between stressed and unstressed articles in all configurations.

The native speakers' productions of articles in both art $+n$ and $\operatorname{art}+\operatorname{adj}+n$ configurations came from the interviewer present in the interviews with SD and two native speakers who were originally recorded in a study by Snape (2009). Snape (2009) replicated the study by Goad and White (2006a, 2008, 2009a) who used an elicited production task, involving a sequence of pictures telling a story. The story was designed to elicit a variety of $\operatorname{art}+n$ and $\operatorname{art}+\mathrm{adj}+\mathrm{n}$ configurations. Subjects had to describe what was happening in their own words. They were recorded using an Apple iPod 5th generation (video) fitted with a Belkin TuneTalk recorder. The data were subsequently transcribed and coded for presence or absence of articles and substitutions. No substitutions of demonstratives or numerals for articles were made by the native speakers. The motivation behind making the comparison between native speakers and SD comes from having some way to determine whether or not SD's productions are similar to those of native speakers.

The data examined in Goad and White (2004) had been transcribed and coded for article use and omission by native speakers of English. However, no acoustic analysis has been carried out to see whether supplied articles have the prosodic structure of Turkish. Therefore, we performed a more detailed analysis of the data from interview 5 to see whether SD's production of articles in $\operatorname{art}+n$ configurations and $\operatorname{art}+\operatorname{adj}+n$ configurations were target-like (unstressed) suppliance. ${ }^{5}$ The interviews were originally recorded using a DAT recorder. The recordings were subsequently placed onto CDs as digital WAV files 
by a student at McGill University, so they could be analysed using Praat. We then used the phonetic analysis software Praat to look at the native speakers' and SD's production of articles and Microsoft Excel XP to code the articles. In order to determine the type of production, Praat was used to isolate individual DPs so a closer analysis of the article could be performed. Partially incomprehensible DPs (e.g. cases with too much background noise) and DPs with hesitations before the article were excluded.

There are three possible measures which can be used to establish whether a particular morpheme receives stress; duration, pitch and intensity (Ladefoged, 2003). For our analysis of the dataset (interview 5) we used duration and pitch measurements to determine if each article was unstressed or stressed. Intensity was considered as being another correlate of stress as the F0 contour is the principal acoustic cue for stress in both Turkish (Levi, 2005) and English (Fry, 1955, 1958), but, Ladefoged (2003) argues that intensity is difficult to measure in acoustic analysis software as it may only show the loudness of the sound or word, which does not make it any more stressed. Therefore, we took duration and/or pitch values as indictors of stress. The duration of the article was measured in each DP. The article was considered to be a stressed article if the duration of the definite article exceeded 120 milliseconds (ms) and the duration of the indefinite article exceeded $100 \mathrm{~ms}$. The duration of the definite and indefinite article differs because the definite article begins with the consonant / $ठ$ / followed by a vowel, whereas the indefinite article is the weak vowel 'schwa'/ə/. If the duration of the definite article was within the range of $10 \mathrm{~ms}$ to $120 \mathrm{~ms}$ it was considered unstressed and if the indefinite article duration was within the range of $10 \mathrm{~ms}$ to $100 \mathrm{~ms}$ it was considered unstressed. The ratio of unstressed to stressed was 2:1. Pitch is another possible indicator of stress. If a pitch fall occurred before and after the article and the fall exceeded -15 hertz $(\mathrm{Hz})$ the article was considered to be stressed.

A target-like use of a definite article by a native English speaker is illustrated below in Figure 10. Figure 10 shows the duration of the article (to the left of the image in the shaded text grid) along with pitch, which is the dotted line. A text grid allows the user of Praat to accurately measure the length of individual sounds or words. The duration of the article is $90 \mathrm{~ms}$ and the pitch measurement on the article $(90 \mathrm{~Hz})$ is lower than the preceding word 'holding' $(153 \mathrm{~Hz})$ and lower than the following word 'channel' $(132 \mathrm{~Hz})$. The duration and pitch indicate that the article in Figure 10 is unstressed. ${ }^{6}$

Figure 11 shows the duration of the indefinite article along with pitch. The duration of the article in Figure 9 is $60 \mathrm{~ms}$ and the pitch measurement on the article $(171 \mathrm{~Hz})$ is about the same as the pitch measured for the preceding word 'like' $(167 \mathrm{~Hz})$. The following word 'placement' has a lower pitch value than the article $(94 \mathrm{~Hz})$. The duration of the article is short and the pitch value on the article is not higher than the previous or following word.

The article represented in Figure 12 was considered to be stressed as the duration is two times longer than its unstressed counterpart. Figure 12 shows a stressed article uttered by a native speaker of English. We found a few uses of stressed articles in the data. One reason for finding any stressed articles, although articles are normally unstressed in English, may be due to the type of task as native speakers sometimes employ contrastive stress on the article and adjective e.g. 'thé réd coat' rather than 'the green coat'. Typically, the vowel receives stress and is longer, i.e., the [ði:] rather than the unstressed schwa form the [ðə]. 


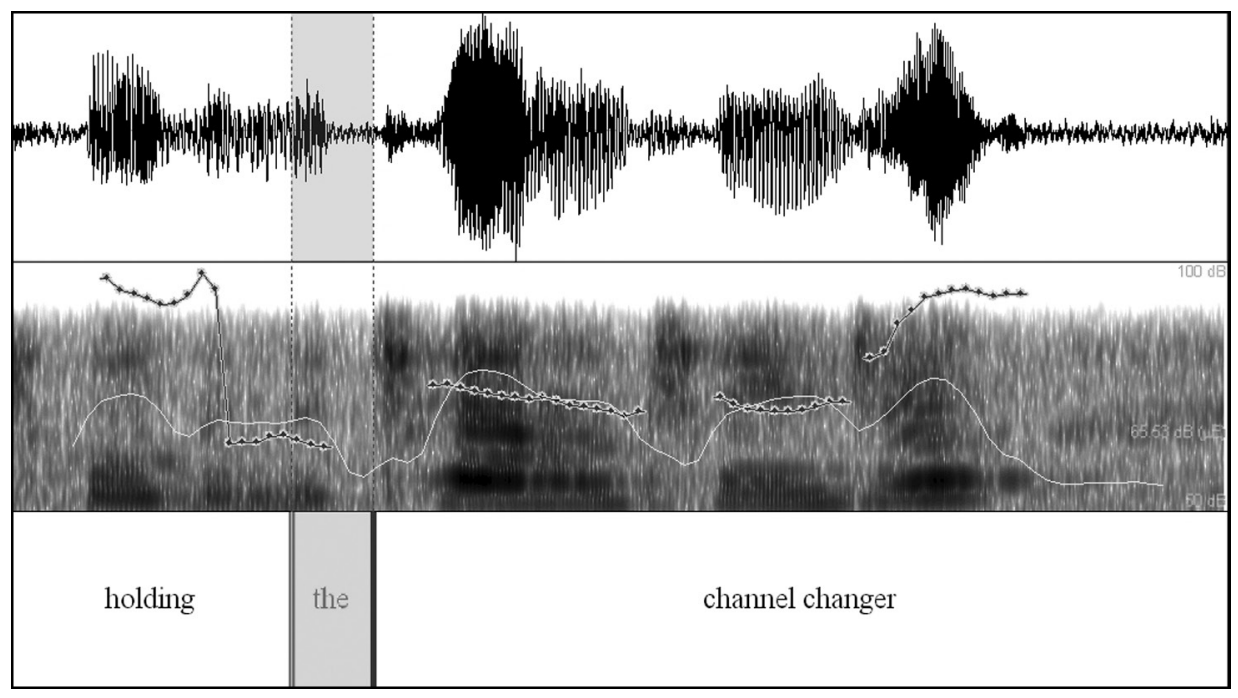

Figure 10 Target-like (unstressed) use of a definite article: example of holding the channel changer

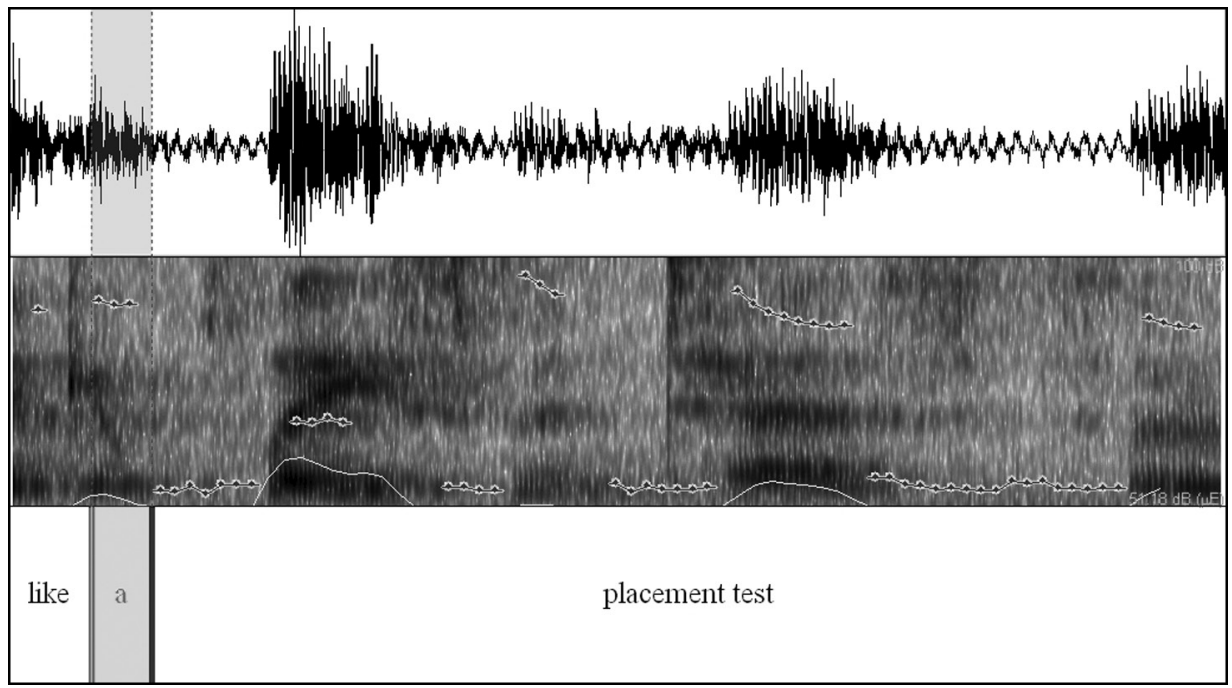

Figure I I Target-like (unstressed) use of an indefinite article: example of like a placement test

\section{Results}

The results from three native speakers are provided in Tables 3 and 4. Suppliance by SD (interview 5) was examined for any substitutions, i.e. demonstratives in place of the or 


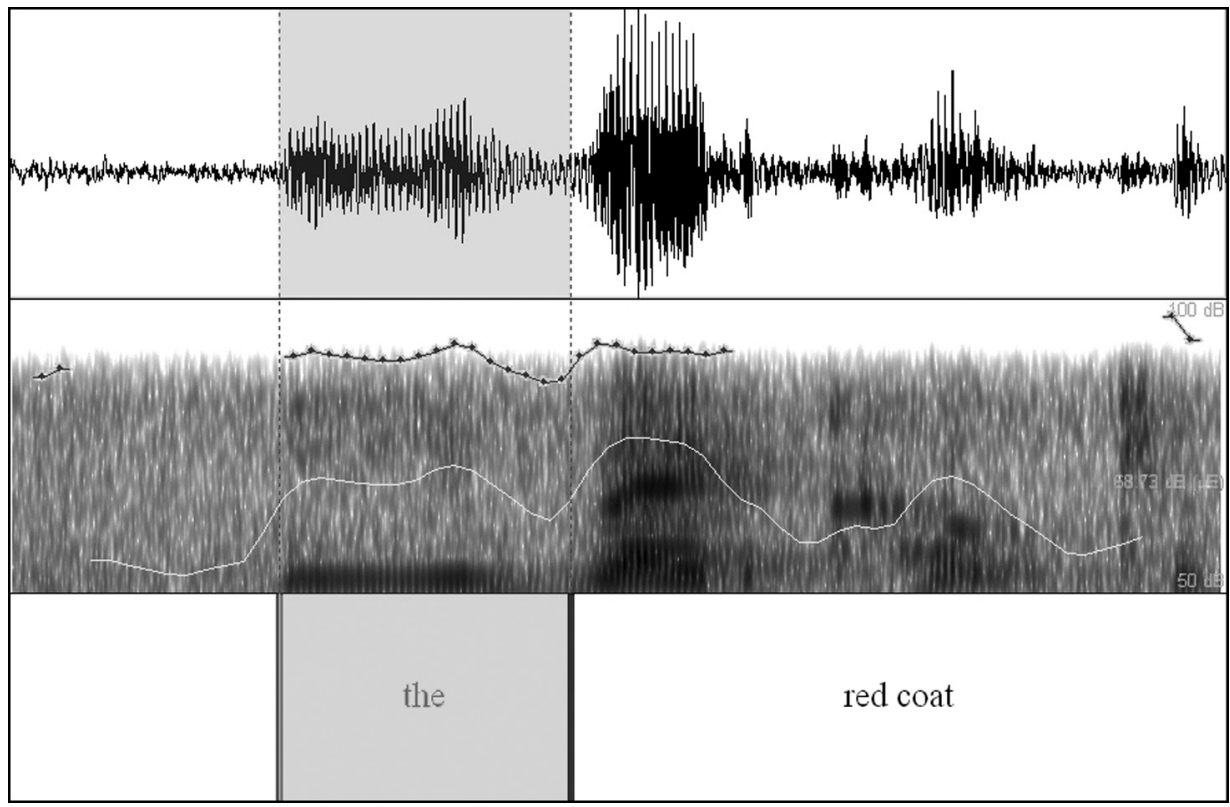

Figure 12 Non target-like (stressed) use of a definite article: example of the red coat

the numeral one in place of $a$. We found a number of demonstratives (this) used in noun configurations $(\operatorname{dem}+n)$ and adjective + noun configurations $(\operatorname{dem}+\operatorname{adj}+n)$. No substitutions of one in place of $a$ were found. ${ }^{7}$ These are presented in Table 5. A total of 39 demonstratives were produced in dem $+n$ configurations and a total of 6 demonstratives were produced in dem + adj $+n$ configurations by SD.

Table 3 Articles produced by native speakers in art $+n$ configurations

\begin{tabular}{llllll}
\hline & \multicolumn{2}{c}{ Definite articles } & & \multicolumn{2}{c}{ Indefinite articles } \\
\cline { 2 - 3 } & Unstressed & Stressed & & Unstressed & Stressed \\
\hline Total number & $16 / 18(88.9 \%)$ & $2 / 18(11.1 \%)$ & & $16 / 16(100 \%)$ & $0 / 16(0 \%)$ \\
Average duration $(\mathrm{ms})$ & 79 & 140 & & 74 & - \\
\hline
\end{tabular}

Table 4 Articles produced by native speakers in art+adj+n configurations

\begin{tabular}{llllll}
\hline & \multicolumn{2}{c}{ Definite articles } & & \multicolumn{2}{c}{ Indefinite articles } \\
\cline { 2 - 3 } & Unstressed & Stressed & & Unstressed & Stressed \\
\hline Total number & $21 / 23(91.3 \%)$ & $2 / 23(8.7 \%)$ & & $26 / 26(100 \%)$ & $0 / 26(0 \%)$ \\
Average duration $(\mathrm{ms})$ & 78 & 185 & & 64 & 125 \\
\hline
\end{tabular}


Table 5 Demonstratives produced by SD in definite configurations

\begin{tabular}{lllll}
\hline & dem+n & def $+n$ & dem+adj+n & def+adj+n \\
\hline $\begin{array}{l}\text { Total number } \\
\begin{array}{l}\text { Average duration of demonstratives } \\
\text { and stressed definite articles }(\mathrm{ms})\end{array}\end{array}$ & $275 / 66(59 \%)$ & $27 / 66(41 \%)$ & $6 / 18(33.3 \%)$ & $12 / 18(66.7 \%)$ \\
\hline
\end{tabular}

Table 6 Total number of articles produced by SD in art $+n$ configurations

\begin{tabular}{llllll}
\hline & \multicolumn{2}{c}{ Definite articles } & & \multicolumn{2}{c}{ Indefinite articles } \\
\cline { 2 - 3 } \cline { 6 - 7 } & Unstressed & Stressed & & Unstressed & Stressed \\
\hline Total number & $8 / 27(29.6 \%)$ & $19 / 27(70.4 \%)$ & & $8 / 18(44.4 \%)$ & $10 / 18(55.6 \%)$ \\
Average duration $(\mathrm{ms})$ & 77 & 147 & & 74 & 142 \\
\hline
\end{tabular}

Table 7 Total number of articles produced by SD in art+adj+n configurations

\begin{tabular}{llllll}
\hline & \multicolumn{2}{c}{ Definite articles } & & \multicolumn{2}{c}{ Indefinite articles } \\
\cline { 2 - 3 } \cline { 6 - 7 } & Unstressed & Stressed & & Unstressed & Stressed \\
\hline Total number & $4 / 12(33.3 \%)$ & $8 / 12(66.7 \%)$ & & $9 / 52(17.3 \%)$ & $43.52(82.7 \%)$ \\
Average duration $(\mathrm{ms})$ & 70 & 182 & & 68 & 182 \\
\hline
\end{tabular}

Note: In our original re-analysis of the data we proposed that SD was producing a number of enclitic articles that were considered to be target-like uses. One reviewer suggests that in the enclitic analysis of, for example, 'in a small office', there will be a slight fall in pitch on 'a', whereas in the pro-clitic analysis of this same phrase there would not be a fall. However, based upon a revised analysis we found that a small number of indefinite articles were target-like in duration and/or pitch - e.g. pro-clitic articles - but there were no instances of enclitic articles based on the reviewer's proposed analysis.

Table 8 Total number of unstressed and stressed articles produced by SD in art $+\mathrm{n}$ configurations

\begin{tabular}{|c|c|c|c|c|}
\hline & \multicolumn{2}{|c|}{ Unstressed articles } & \multicolumn{2}{|c|}{ Stressed articles } \\
\hline & def $+n$ & indef $+n$ & def $+n$ & indef $+n$ \\
\hline Total number & $8 / 27$ (29.6\%) & 8/I8 (44.4\%) & 19/27 (70.4\%) & I0/I8 (55.6\%) \\
\hline
\end{tabular}

Table 9 Total number of unstressed and stressed articles produced by SD in art+adj+n configurations

\begin{tabular}{llllll}
\hline & \multicolumn{2}{c}{ Unstressed articles } & & \multicolumn{2}{c}{ Stressed articles } \\
\cline { 2 - 3 } & def + adj $+n$ & indef + adj $+n$ & & def + adj $+n$ & indef + adj $+n$ \\
\hline Total number & $4 / 12(33.3 \%)$ & $9 / 52(17.3 \%)$ & & $8 / 12(66.7 \%)$ & $43 / 52(82.7 \%)$ \\
\hline
\end{tabular}


All cases of overt articles supplied in $\operatorname{art}+n$ configurations and $\operatorname{art}+\operatorname{adj}+n$ configurations, either unstressed or stressed, are presented in Tables 6 and $7 .^{8}$ There is no significant contingency between DPs with unstressed and stressed articles in art $+\mathrm{n}$ configurations $\left(\chi^{2}=0.49, \mathrm{df}=1, p=0.48\right)$.

The Fisher's exact probability test (two-tailed) reveals no significant association between DPs with unstressed and stressed articles in art + adj $+n$ configurations $(p=0.24)$. A comparison between the unstressed and stressed articles in $\operatorname{art}+n$ and $\operatorname{art}+\operatorname{adj}+n$ configurations revealed that there is a significant difference $\left(\chi^{2}=17.86, \mathrm{df}=1, p<0.001\right)$.

For definite articles, no significant difference was found between unstressed and stressed definite articles in all configurations. For indefinite articles, the Fisher's exact probability test (two-tailed) shows a significant difference between unstressed and stressed indefinite articles in all configurations $(p=0.05)$. In sum, the results from DPs with stressed articles in art $+\mathrm{adj}+\mathrm{n}$ configurations show that SD tends to stress articles more often when adjectives are present in indefinite $\operatorname{art}+\operatorname{adj}+n$ configurations. The results show the predicted asymmetry is in the right direction, in other words, stressing articles significantly more in the presence of an adjective.

Comparisons between SD and the native speakers were made to find out if suppliance of unstressed and stressed articles is significantly different. There is a significant difference between unstressed and stressed definite articles in art $+\mathrm{n}$ configurations $\left(\chi^{2}=12.95\right.$, df $=1, p<0.01$ ). The Fisher's exact probability test (two-tailed) reveals a significant difference between unstressed and stressed indefinite articles in $\operatorname{art}+\mathrm{n}$ configurations $(p<0.01)$. In the art + adj $+n$ configurations the Fisher's exact probability test (two-tailed) shows a significant difference between unstressed and stressed definite articles in $\operatorname{art}+\mathrm{adj}+\mathrm{n}$ configurations $(p<0.01)$. A chi square test reveals that there is a significant difference between unstressed and stressed indefinite articles in $\operatorname{art}+\mathrm{adj}+\mathrm{n}$ configurations $\left(\chi^{2}=44.63, \mathrm{df}=1, p<0.001\right)$.

We believe that the results of SD's article suppliance are consistent with the strong interpretation of the PTH. We discuss the results and the implications of the results in the following section.

\section{Discussion}

To summarize, in this article we re-examined data which were originally collected by White (2003). Goad and White (2004) conducted a follow-up study examining the data from all five interviews. In our analysis we looked at data from one interview, interview 5 (Time 2), and provided a phonetic analysis. Like Goad and White, we found a number of definite and indefinite articles supplied in $\operatorname{art}+\mathrm{n}$ and $\operatorname{art}+\mathrm{adj}+\mathrm{n}$ configurations, but in our reanalysis of the data we discovered that the suppliance of articles consisted of two types: unstressed and stressed articles. SD is able to supply a limited number of unstressed articles in both configurations, but there is an asymmetry between the number of unstressed indefinite articles in art $+\mathrm{n}$ configurations and unstressed indefinite articles in $\operatorname{art}+\mathrm{adj}+\mathrm{n}$ configurations. One reason for the asymmetry might be that Turkish lacks the corresponding L1 representation for bir in adj $+n$ configurations (see Figure $4 \mathrm{~b}$ above). The adjective separates the unstressed indefinite article and noun, and as bir cannot prefix onto an adjective the interpretation is not ill-formed, but bir is prosodically dependent 
on the head noun. Previously, in Goad and White (2004), it was argued under the strong interpretation of the PTH that SD is more likely to delete articles before adjectives as representations are not available or not appropriate. But, they found SD was able to supply articles in $\operatorname{art}+\mathrm{adj}+\mathrm{n}$ configurations even though there is no corresponding L1 prosodic structure. Firstly, we discuss article suppliance in $\operatorname{art}+\mathrm{n}$ configurations and $\operatorname{art}+\mathrm{adj}+\mathrm{n}$ configurations. Secondly, we discuss the asymmetry found between unstressed indefinite articles in $\operatorname{art}+n$ configurations and unstressed indefinite articles in $\operatorname{art}+\operatorname{adj}+n$ configurations.

A number of articles were supplied by SD in art $+n$ configurations. Though no significant difference was found between unstressed and stressed articles there is a tendency for SD to stress articles (see Table 6). In Sections III and V we presented the prosodic representations in English and Turkish and predicted that SD will be able to supply articles in art $+n$ configurations as (1) there is the affixal clitic representation available in the L1 which can be adapted to represent articles in the L2 or (2) the structure whereby the demonstrative bú (this) or numeral bir (one) is stressed and is an independent PWd (see examples 5 above). But, SD not only stresses a number of definite articles, she also substitutes definite articles for demonstratives (see Table 5). The fact that SD prefers to stress articles seems to suggest that she is avoiding the affixal clitic representation, the non target-like representation for articles in English. In the case of definite articles, there is a high substitution of demonstratives which are stressed in English, thus SD directly transfers the L1 structure to the L2 representing demonstratives as independent PWds. No stressed numerals, e.g. one, were substituted for the indefinite article, and very few unstressed indefinite articles were supplied by SD in art $+n$ configurations (a total of 8 out of 18). SD mainly seems to avoid using the non target-like representation for articles and opts for the L1 structure, i.e. representing the indefinite article as a stressed independent PWd.

In $\operatorname{art}+\mathrm{adj}+\mathrm{n}$ configurations a number of articles were supplied by SD (see Table 7). A quick glance at Table 7 shows that most of the articles supplied are stressed. As predicted in Section V, SD has greater problems with target-like suppliance of unstressed articles because the prosodic structure for $\operatorname{art}+\mathrm{adj}+\mathrm{n}$ configurations is unavailable in the L1. As a result, SD tends to resort to representing articles as stressed independent PWds as the equivalent structure is available in the L1. The asymmetry found between unstressed indefinite articles in art $+n$ configurations and unstressed indefinite articles in $\operatorname{art}+\mathrm{adj}+\mathrm{n}$ configurations can be accounted for easily because SD is able to use the L1 affixal clitic structure to represent L2 articles. SD could adapt existing structures to represent articles in art $+a d j+n$ configurations (see Figure $8 b$ ) and she is partly successful as there are some target-like uses, but there are very few unstressed tokens in definite (4 out of 12) and indefinite ( 9 out of 52) contexts. We believe that though the strong interpretation of the PTH rules out target-like suppliance, the fact that target-like suppliance is so low, is still consistent with the strong interpretation.

In a previous (unpublished) version of this article, we argued for a PWd-internal analysis for enclisis as we claimed that some of the articles SD produces are enclitic (see also footnote 7). Under the enclitic analysis the article would occur within the PWd with the preceding word as follows: $\left[[\text { in-a }]_{\mathrm{PWd}}\left[\mathrm{small}_{\mathrm{PWd}}[\text { office }]_{\mathrm{PWd}}\right]_{\mathrm{PPh}}\right.$, as suggested e.g. by Demuth and McCullough (2009) for L1-acquisition. With this representation, transfer would predict that articles get stressed (and undergo vowel harmony; see Goad and 
White, 2009b). In order to answer the question of whether articles are enclitic, acoustic measurements (F1 and F2 values) of vowels in the article and the first vowel of the following lexical item (noun or adjective) need to be examined.

We examined the data from interview 5 (Time 2), assuming with White (2003) that interview 5 represents SD in an endstate. White (2003) found no difference in suppliance of determiners and verbal morphology between the four interviews (Time 1) and the fifth interview (Time 2) and argued that SD is at the endstate, as she has lived in Canada with extensive exposure to and use of English for a ten-year period. We found from our analysis of the data from interview 5 that SD supplies a large number of stressed articles, thus avoiding the target-like representation of articles. Another avoidance strategy SD employs is to delete articles, especially when a modifier is present between the article and noun. We argue that our findings are consistent with the strong interpretation of the PTH, which states that learners are unable to build or modify existing prosodic structures.

One remaining issue, which Goad and White (2004) address, is whether SD has full or partial access to UG in the domain of prosodic phonology. They argue that the absence of L2 structures unavailable in the L1 suggests only partial access. More specifically, SD can be argued to have only partial access to UG because she has not acquired the representation for free clitics, as found in English but not in Turkish. In other words, the building blocks which permit linking to the PPh are not among the existing licensing relations in SD's L1 or her interlanguage representations of the L2. We feel that the analysis we provide in the present article may go some way in contributing to the discussion of whether or not SD has full or partial access. Evidence from SD's article suppliance suggests that she has only partial access to UG in the domain of prosodic phonology (in contrast to full access in the syntax) as new structures are not licensed. This is consistent with the notion of minimal adaption in (8).

\section{Conclusion}

By using the acoustic analysis program Praat we have been able to establish that there are a number of definite and indefinite articles which appear to be stressed in the speech of $\mathrm{SD}$, an endstate speaker of English. We found that articles in art $+\mathrm{adj}+\mathrm{n}$ configurations are more likely to be stressed as SD lacks the corresponding structure in her interlanguage grammar to represent articles as free clitics, i.e. articles that join directly to the $\mathrm{PPh}$. To conclude, we believe that our findings support the idea that SD lacks the appropriate prosodic structures for English articles and thus uses avoidance strategies such as stressing articles, substituting articles for demonstratives or deleting articles in obligatory contexts. We argued that our results are consistent with the strong version of the Prosodic Transfer Hypothesis.

\section{Acknowledgements}

We would like to thank a number of people for their help and suggestions: John Archibald, Julien Eychenne, Mary Grantham O'Brien, Christine Shea and Lydia White. A special thanks goes to Heather Goad and two anonymous Second Language Research reviewers for the useful comments and suggestions on an earlier version of our article. The authors are solely responsible for any errors or misinterpretations. 


\section{Notes}

1 The star that appears before the omitted article $\varnothing$ signifies that this is ungrammatical since syntactically an article (the or $a$ ) is required to appear before the noun 'dog' and the modified 'brown dog'.

2 Trenkic (2007) proposes a syntactic misanalysis account for L2 article acquisition. For Trenkic, article production is lexically based as articles are treated as lexical words and pragmatically motivated if there is a perceived need to express the meaning they encode (for the learner).

3 Goad and White (2004) provide an explanation of vowel harmony as to why indefinite bir (unstressed) is outside the lower PWd.

4 Substitution here refers to the substitution of the and $a$ by other determiners or numerals, not substitution of the for $a$ and vice versa.

5 We thank Heather Goad and Lydia White for allowing us to have access to SD's data files.

6 Sometimes, especially when the article is short, the pitch contour is interrupted unexpectedly, despite the production of a vowel. This could be due to 'creaky voice', the vowel is voiceless (inhaled), or the wave form has very low amplitude.

7 We limit our discussion of substitutions to demonstratives as there were very few possessives and quantifiers produced by SD.

8 Goad and White (2006a) argue that another strategy for avoiding the target-like representation is to insert a filler or pause between the article and noun or article and adjective. A filler is not prosodified or, if it is, it would not directly attach to the $\mathrm{PPh}$, as it has no lexical content; instead it would be separate from the noun and form its own PPh. A pause between the article and noun can be prosodified as an independent PWd. However, there a number of reasons why L2 speakers might insert fillers or pauses, for example, for reasons of oral production task effects (communication pressure) which hinder lexical retrieval.

\section{References}

Abney SP (1987) The English noun phrase in its sentential aspect. Unpublished PhD thesis, MIT, Cambridge, MA.

Boersma P and Weenink D (2006) Praat: Doing phonetics by computer, version 4.5.05 [Computer program]. Retrieved from http://www.praat.org (July 2010).

Demuth K and McCullough E (2009) The prosodic (re)organization of children's early English articles. Journal of Child Language 36: 173-200.

Demuth K and Tremblay A (2008) Prosodically-conditioned variability in children's production of French determiners. Journal of Child Language 35: 99-127.

Fry D (1955) Duration and intensity as physical correlates of linguistic stress. Journal of the Acoustical Society of America 35: 765-69.

Fry D (1958) Experiments in the perception of stress. Language and Speech 1: 126-52.

Goad H and Buckley M (2006) Prosodic structure in child French: Evidence for the foot. Catalan Journal of Linguistics: Special issue on the Acquisition of Romance Languages 5: 109-42.

Goad H and White L (2004) Ultimate attainment of L2 inflections: Effects of L1 prosodic structure. In: Foster-Cohen S, Ota M, Sharwood Smith M, and Sorace A (eds) EuroSla Yearbook. Amsterdam: John Benjamins, 119-45.

Goad H and White L (2006a) Prosodic transfer: L1 Effects on the production of L2 determiners. In: Bamman D, Magnitskaia T, and Zaller C (eds) Proceedings of the 30th Annual Boston University Conference on Language Development (BUCLD). Somerville, MA: Cascadilla Press, 213-24. 
Goad $\mathrm{H}$ and White L (2006b) Ultimate attainment in interlanguage grammars: A prosodic approach. Second Language Research 3: 243-68.

Goad H and White L (2007) Prosodic transfer and determiners in Turkish-English interlanguage. In: Caunt-Nulton H, Kulatilake S, and Woo I-H (eds) Proceedings of the 31st Annual Boston University Conference on Language Development (BUCLD). Somerville, MA: Cascadilla Press, 230-38.

Goad H and White L (2008) Prosodic structure and the representation of L2 functional morphology: A nativist approach. Lingua 118: 577-94.

Goad H and White L (2009a) Prosodic transfer and the representation of determiners in TurkishEnglish interlanguage. In: Snape N, Leung Y-KI, and Sharwood Smith M (eds) Representational deficits in SLA: Studies in honor of Roger Hawkins. Amsterdam: John Benjamins, 1-26.

Goad H and White L (2009b) Articles in Turkish/English interlanguage revisited: Implications of vowel harmony. In: García-Mayo MP and Hawkins R (eds) Second language acquisition of articles: Empirical findings and theoretical implications. Amsterdam: John Benjamins, 201-32.

Goad H, White L, and Steele J (2003) Missing inflection in L2 acquisition: Defective syntax or L1-constrained prosodic representations? Canadian Journal of Linguistics 48: 243-63.

Hawkins R, Al-Eid S, Almahboob I, Athanasopoulos P, Chaengchenkit R, Hu J, Rezai M, Jaensch C, Jeon Y, Jiang A, Leung I, Matsunaga K, Ortega M, Sarko G, Snape N, and Velasco-Zarate $\mathrm{K}$ (2006) Accounting for English article interpretation by L2 speakers. In: Foster-Cohen SH, Krajnovic MM, and Djigunović JM (eds) EUROSLA Yearbook 6. Amsterdam: John Benjamins, 7-25.

Ionin T, Ko H, and Wexler K (2004) Article semantics in L2-acquisition: The role of specificity. Language Acquisition 12: 3-69.

Kornfilt J (1997) Turkish. London: Routledge.

Kupisch T, Anderssen M, Bohnacker U, and Snape N (2009) Article acquisition in English, German, Norwegian and Swedish. In: Ronald W, Héctor Campos L, and Lardiere D (eds) Georgetown University Round Table on Languages and Linguistics (GURT) 2007 Proceedings. Washington, DC: Georgetown University Press, 223-35.

Ladefoged P (2003) Phonetic data analysis: An introduction to fieldwork and instrumental techniques. Oxford: Blackwell.

Lardiere D (2004) Knowledge of definiteness despite variable article omission in second language acquisition. In: Brugos A, Micciulla L, and Smith CE (eds) Proceedings of the 28th Annual Boston University Conference on Language Development (BUCLD). Somerville, MA: Cascadilla Press, 328-39.

Levi SV (2005) Acoustic correlates of lexical accent in Turkish. Journal of the International Phonetic Association 35: 73-97.

Lleó C and Demuth K (1999) Prosodic constraints on the emergence of grammatical morphemes: Crosslinguistic evidence from Germanic and romance languages. In: Greenhill A, Hughes M, Littlefield H, and Walsh $\mathrm{H}$ (eds) Proceedings of the 23rd Boston University Conference on Language Development (BUCLD). Somerville, MA: Cascadilla Press, 407-18.

Lyons C (1999) Definiteness. Cambridge: Cambridge University Press.

Nespor M and Vogel I (1986) Prosodic phonology. Dordrecht: Foris.

Öztürk B (2005) Case, referentiality and phrase structure. Linguistik Aktuell [Linguistics Today], Volume 77. Amsterdam: John Benjamins.

Schwartz BD and Sprouse R (1996) L2 cognitive states and the Full Transfer/Full Access model. Second Language Research 12: 40-72. 
Selkirk EO (1986) On derived domains in sentence phonology. Phonology 3: 371-405.

Selkirk EO (1996) The prosodic structure of function words. In: Morgan JL and Demuth K (eds)

Signal to syntax: Bootstrapping from speech to grammar in early acquisition. Mahwah, NJ: Lawrence Erlbaum, 187-213.

Snape N (2008a) Resetting the nominal mapping parameter: Definite article use and the countmass distinction in L2 English. Bilingualism: Language and Cognition 11: 63-79.

Snape N (2008b) The acquisition of the English determiner phrase by L2 learners: Japanese and Spanish. Saarbrücken: VDM Verlag.

Snape N (2009) Exploring Mandarin Chinese speakers' article use. In: Snape N, Leung Y-KI, and Sharwood Smith M (eds) Representational deficits in SLA: Studies in honor of Roger Hawkins. Amsterdam: John Benjamins, 27-51.

Trenkic D (2002) Form-meaning connections in the acquisition of English articles. In: FosterCohen S, Ruthenberg T, and Poschen ML (eds) EUROSLA Yearbook 2. Amsterdam: John Benjamins, 115-33.

Trenkic D (2007) Variability in L2 article production: Beyond the representational deficits vs. processing constraints debate. Second Language Research 23: 289-327.

Underhill R (1976) Turkish grammar. Cambridge, MA: MIT Press.

White L (2003) Fossilization in steady state L2 grammars: Implications of persistent problems with inflectional morphology. Bilingualism: Language and Cognition 6: 129-41.

White L (2008) Definiteness effects in the L2 English of Mandarin and Turkish speakers. In: Chan $\mathrm{H}$, Jacob H, and Kapia E (eds) Proceedings of the 32nd Annual Boston University Conference on Language Development (BUCLD). Somerville, MA: Cascadilla Press, 550-61.

White L, Belikova A, Hagstrom P, Kupisch T, and Özçelik Ö (2009) Restrictions on definiteness in L2 English. In: Chandlee J, Franchini M, Lord S, and Rheiner GM (eds) Proceedings of the 33rd annual Boston University Conference on Language Development (BUCLD). Somerville, MA: Cascadilla Press.

Young R (1996) Form-function relations in articles in English interlanguage. In: Bayley R and Preston DR (eds) Second language acquisition and linguistic variation. Amsterdam: John Benjamins, 135-75. 